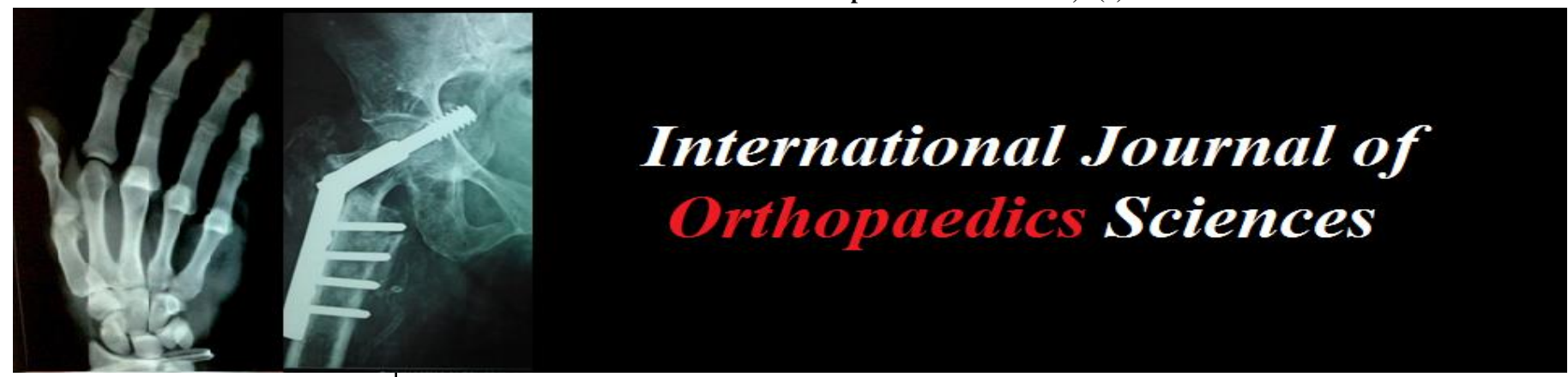

ISSN: $2395-1958$

IJOS 2018; 4(3): 78-81

(C) 2018 IJOS

www.orthopaper.com

Received: 16-05-2018

Accepted: 17-06-2018

Dr. Jawahar Mehmood Khan JR Department of Orthopaedics GMC, Jammu and Kashmir, India

Dr. Mohd Irfan Banday Orthopaedic Surgeon J\&K

Health Services, Jammu and

Kashmir, India

Dr. Jabreel Muzaffar

SR department of orthopaedics Shri Mahant Indresh Hospital Dehradun, Uttarakhand, India

Correspondence

Dr. Jawahar Mehmood Khan

JR Department of Orthopaedics

GMC, Jammu and Kashmir,

India

\section{A study of measurement of acetabular diameter radiologically in northern Indian population of Jammu region}

\author{
Dr. Jawahar Mehmood Khan, Dr. Mohd Irfan Banday and Dr. Jabreel \\ Muzaffar
}

DOI: https://doi.org/10.22271/ortho.2018.v4.i3b.16

\begin{abstract}
The acetabulum is a cup-shaped socket of the hipbone that derives its name from its resemblance to a shallow Roman vinegar cup. In clinical medicine, measurements of the acetabulum are crucial in diagnosis, monitoring patient recovery, determining stability of the hip joint and in assessment of acetabular dysplasia. The decision for operative treatment is often based on different radiographic measurements and scores for which normal values are defined. Therefore orthopaedic surgeons often use combinations of measurements when assessing acetabular parameter. A number of authors have also shown that geometrical measurements of acetabulam differ with respect to age, sex, and race and even within regions. The size, shape and depth of the acetabulum are variable as reported by Govsa $\mathrm{F}$ et al., Therefore, the knowledge of various parameters of acetabulum would be helpful in performing surgical procedures such as acetabular reconstruction and planning reorientation procedures using spikes and screws for fixation.
\end{abstract}

Keywords: Distal femoral fractures, treatment modalities, conservative Vs operative

\section{Introduction}

The acetabulum is a cup-shaped socket of the hipbone that derives its name from its resemblance to a shallow Roman vinegar cup. The acetabulum forms from the coalescence of three ossification centers (collectively called the 'triradiate cartilage'): ilium, pubis and ischium. The triradiate cartilage gives rise to the anterior wall, posterior wall and the dome of the acetabulum. The triradiate cartilage subsequently closes between ages 14 to 16 . The acetabulum has an average diameter of $52 \pm 4 \mathrm{~mm}$. Men tend to have larger diameters compared to women. Average anteversion of the native acetabulum measures 16 to 21 degrees with an average inclination of 48 degrees. Men tend to have less anteversion than females. The transverse acetabular ligament, located inferiorly, connects the anterior and posterior walls of the acetabulum forming a tension band against deformation of the wall from force transmission. The acetabulum is supported by two strong columns of bone. The anterior and posterior columns connect the acetabulum to the pelvis and allow force transmission between the trunk and the lower extremity.

The acetabular fossa is a central cavity containing the ligamentum teres and a fat pad called pulvinar. The ligamentum teres connects the acetabulum to the fovea of the femoral head. It has been hypothesized to be a pain generator and instrumental in synovial fluid distribution and stability. The labrum, which arises from the limbus, is a ring of connective tissue surrounding the outer edge of the acetabulum.

\section{Materials and methods}

The study was conducted in Government Medical College Jammu from October 2016 to November 2017 on the pelvic radiographs of 300 patients. All age groups of the patients who had undergone for pelvic X-ray AP view routinely for their clinical indication with radiologically normal xrays were included in the study. These pelvic radiographs were obtained using the standardised protocol: in 15-30 degrees of internal rotation of the hips in the 
supine position with a film-focus distance of $100 \mathrm{~cm}$ and the beam centered on the symphysis pubis. The magnification power of $\mathrm{x}$ ray machine was kept $54 \%$. The values were calculated by multiplying by factor 1.85 .

The observations and measurements were made with regards to acetabular diameter. All other data like age, sex, presenting complaints were being collected from available records at the Medical records department. This collected data was tabulated

and analysed. Appropriate stastical technique was applied and help of statistician was sought to find out prevalence and significance of any apparent association based on type of data available. Data was distributed normally with the help of statistician of our medical college for comparison of genders.

\section{Acetabular size}

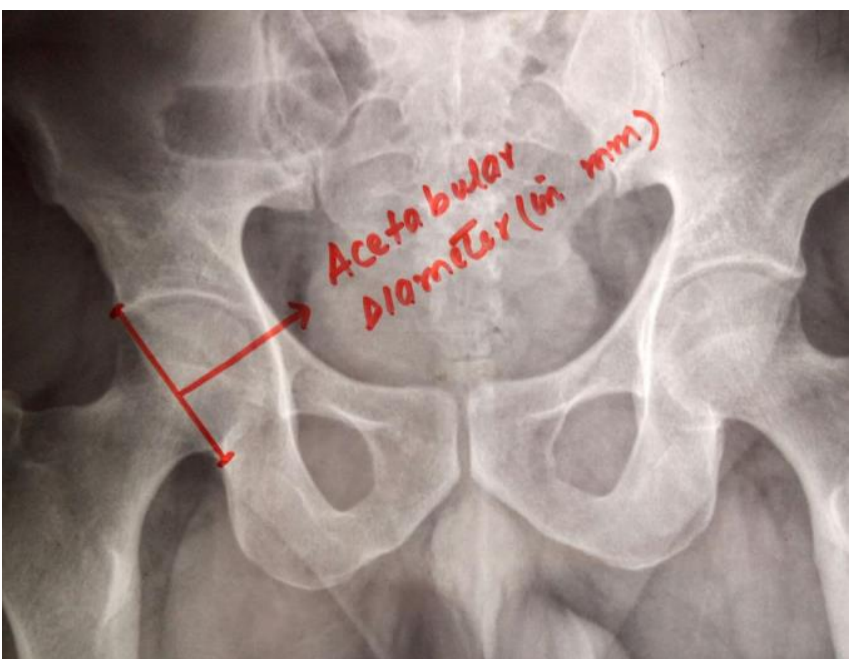

\section{Inclusion Criteria}

All age groups who had gone to get an x-ray of pelvis for any clinical indication on routine basis in OPD/Emergency/Ward in the Department of Orthopaedics of Govt. Medical College Jammu were included in the study.

\section{Exclusion Criteria}

Radiographs of patients with osteoarthritis, metabolic diseases, hip fractures and pathological (metastatic) hip fracture were excluded from the study.

\section{Statistical analysis}

Appropriate stastical technique was applied to find out prevalence and significance of any apparent association based on type of data available.

\section{Observations}

The following observations were made in this study. We included 300 radiographs of pelvii in this study. 168 belonged and 132 were females.

Total number of males and females

\begin{tabular}{|c|c|}
\hline Sex & No. of X Rays \\
\hline Male & 168 \\
\hline Female & 132 \\
\hline
\end{tabular}

Age wise distribution

\begin{tabular}{|c|c|c|c|}
\hline Age Group & No. of Males & No. of Females & Total \\
\hline $10-20$ & 19 & 09 & 28 \\
\hline $21-30$ & 35 & 31 & 66 \\
\hline $31-40$ & 45 & 35 & 80 \\
\hline $41-50$ & 39 & 23 & 62 \\
\hline $51-60$ & 20 & 20 & 40 \\
\hline $61-70$ & 10 & 14 & 24 \\
\hline & 168 & 132 & 300 \\
\hline
\end{tabular}

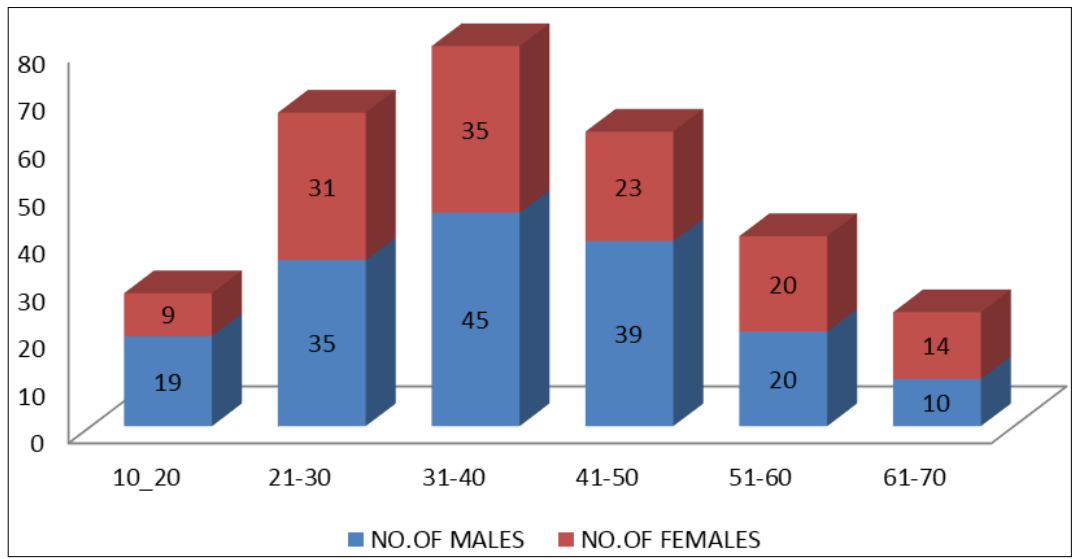


Observation of acetabular diameter age and sex wise

\begin{tabular}{|c|c|c|}
\hline Age Group (Years) & Male (In Mm) & Female (In Mm) \\
\hline $10-20$ & $60.89(50-69)$ & $58(52-66)$ \\
\hline $21-30$ & $60.08(45-74)$ & $60.19(52-70)$ \\
\hline $31-40$ & $59.80(44-69)$ & $60.68(54-68)$ \\
\hline $41-50$ & $58.56(40-74)$ & $61.17(54-70)$ \\
\hline $51-60$ & $60.75(42-74)$ & $60.95(54-70)$ \\
\hline $61-70$ & $59.50(56-65)$ & $59.85(54-66)$ \\
\hline Average & $59.94(40-74)$ & $59.72(52-70)$ \\
\hline
\end{tabular}

Distribution according to acetabular diameter

\begin{tabular}{|c|c|c|c|}
\hline & $\mathbf{N}$ & Mean & SD \\
\hline Male & 168 & 59.94 & 0.85 \\
\hline Female & 132 & 59.72 & 1.15 \\
\hline
\end{tabular}

$\mathrm{N}=$ No Of Observations. Sd = Standard Deviation

The mean acetabular size in males was $59.94 \pm 0.85 \mathrm{~mm}(40-$ 74). The mean acetabular size in females was 59.72 \pm 1.15 $\mathrm{mm}$ (52-70). The difference in the mean acetabular size of males and females was found to be statistically insignificant ( $\mathrm{p}$ value is 0.05 ).

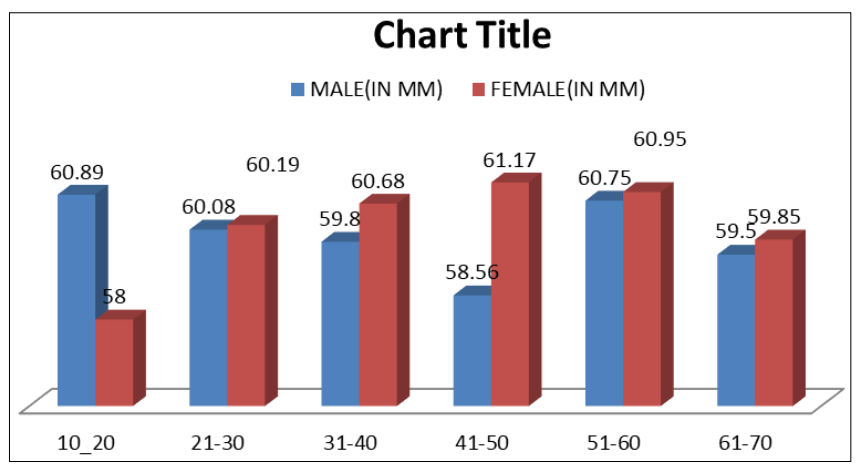

\section{Discussion}

The studies on acetabular diameter have been done in different authors in different parts of the world. Variations in acetabular diameter has been found and this can be attributed to varying level of activity, genetics, race, diet and lifestyle. Despite lot of research in the anatomic and biomechanical factors which influence the modality of treatment of orthopaedics conditions, consideration of acetabular diameter has gained less importance in assessment of hip biomechanics and preoperative planning and templating of hip surgeries. Present study was aimed to measure hip joint anthropometry radiologically in our region and compare it to the studies available and to find if any difference exists. We measured acetabular size on standard AP view radiograph of people attending our hospital who required pelvis radiograph with otherwise normal hip joints.

It is necessary to evaluate the diameter of the acetabulum as part of the preoperative planning in order to estimate the size of the acetabular cup in the surgical procedure of the acetabulum, especially in total hip arthroplasty. The measurement of the acetabular diameter was performed in the anteroposterior view of the pelvic radiograph, and the commercial template is routinely used to solve the magnification problem and to estimate the size of the acetabulum and the prosthesis. The acetabular diameter in our study was $59.84 \mathrm{~mm}$, for males it was $59.94 \mathrm{~mm}$ and for females it was $59.72 \mathrm{~mm}$. Comparing with studies from Thailand, Bavornrt Chukpaiwong and Nam Chai had $54.29 \mathrm{~mm}$ and $51.82 \mathrm{~mm}$ respectively. In a cadaveric study from USA by Munif A Hatem in skeletons from Clevland Museum, the acetabular diameter was found $51 \mathrm{~mm}$ in males and 45.53 inn females. This difference may be due to racial diversity in various skeletons of Museum.

\begin{tabular}{|c|c|}
\hline Study & Acetabular diameter (in mm) \\
\hline Bavornrt chukpaiwong & 54.29 \\
\hline Nam Chai & 51.82 \\
\hline Munif A Hatem & 51 in males / 45.53 females \\
\hline Present study & 59.84 \\
\hline
\end{tabular}

Overall our results are comparable to most of the studies consisting of identical ethinicity population. The differences observed in acetabular diameter measurement obtained may be due to some being directly obtained from the dry bones while others from radiological studies of patients and radiographic examination in dry femurs and there may be some differences among observers also.

\section{Summary and conclusion}

This study concludes that there are no significant differences in acetabular diameter among north Indian population compared to ethinically similar populations. Significant differences exist between Indian and European and Africian anthropometry. Within Indian population also, the anthropometric parameters vary from region to region, hence this study may be useful for designing the total hip prosthesis among the Indian population. Awareness of the average dimensions of the acetabulum and femoral head will assist prosthetists in designing a suitable prosthesis according to the need of a particular individual.

However our study was small with only 300 persons. A large multicentric study is needed to confirm our results.

\section{References}

1. Anda S, Svenningsen S, Dale LG, Benum P. The acetabular sector angle of the adult hip determined by computed tomography. Acta Radiol Diagn, 1986; 27:4437.

2. Anda S, Terjesen T, Kvistad KA. Computed tomography measurements of the acetabulum in adult dysplastic hips: which level is appropriate?. Skeletal Radiol. 1991; 20:267-71.

3. Haddad FS, Garbuz DS, Duncan CP, Janzen DL, Munk PL. CT evaluation of periacetabular osteotomies. J Bone Joint Surg (Br). 2000; 82:52.

4. Hipp JA, Sugano N, Millis MB, Murphy SB. Planning acetabular redirection osteotomies based on joint contact pressures. Clin Orthop. 1999; 364:134-43.

5. Janzen DL, Aippersbach SE, Munk PL, Sallomi DF, Gar buz D, Werier $\mathrm{J}$ et al. Three-dimensional CT measurement of adult acetabular dysplasia: technique, preliminary results in normal subjects, and potential applications. Skeletal Radiol. 1998; 27:352-8.

6. Klaue K, Wallin A, Gantz R. CT evaluation of coverage and congruency of the hip prior to osteotomy. Clin Orthop. 1988; 232:15-25.

7. Lequesne M, de Sèze S. Le faux profile du bassin: Nouvelle incidence radiographique pour lètude de la hance. Son utilite dans les dysplasies et les differentes coxopathies. Rev Rhum Mal Osteoartic. 1961; 28:643-52.

8. Murphy SB, Kijewski PK, Millis MB, Harless A. Acetab ular dysplasia in the adolescent and young adult. Clin Orthop. 1990; 261:214-23.

9. Sanchez-Sotelo J, Berry DJ, Trousdale RT, Cabanela ME. Surgical treatment of developmental dysplasia of the hip in adults: II. Arthroplasty options. J Am Acad Orthop 
Surg. 2002; 10:334-44.

10. Tallroth K. Developmenetal dysplasia of the hip2: Adult. Imaging of the hip \& bony pelvis, A MDavies, K Johnson, R W Whitehouse. Springer, Berlin Heidelberg New York, 2005, 125-40.

11. Tönnis D. Congenital dysplasia and dislocation of the hip in children and adults. Springer, Berlin Heidelberg New York, 1987

12. Trumble SJ, Mayo KA, Mast JW. The periacetabular osteotomy. Minimum 2 year followup in more than 100 hips. Clin Orthop. 1999; 363:54-63.

13. Wiberg G. Studies on dysplastic acetbaula and congenital subluxation of the hip joint: With special reference to the complication of osteo-arthritis. Acta Chir Scand. 1939; 83(58):1-135. 